\title{
Racial/Ethnic and Socioeconomic Disparities in Use of Direct-Acting Antivirals Among Medicare Beneficiaries with Chronic Hepatitis C, 2014-2016
}

\author{
Jeah Jung, PhD, MPH; Ping Du, MD, PhD; Roger Feldman, PhD; \\ Lan Kong, PhD; and Thomas Riley, III, MD, MS, FAASLD
}

\begin{abstract}
BACKGROUND: New hepatitis C virus (HCV) drugs-direct-acting antivirals (DAAs) - are highly effective but costly, which raises a concern about limited access to DAAs by vulnerable populations. Previous studies of disparities in DAA use across patient groups showed mixed results, but their generalizability was limited due to using data from commercial insurers or from 2014 only-the first year DAAs were available. Disparities in DAA use in a national cohort in the years when more DAAs were available is unknown.
\end{abstract}

OBJECTIVE: To examine whether disparities in DAA use by patient race/ ethnicity and socioeconomic status in Medicare changed between 2014 and 2016

METHODS: The study population was made up of chronic hepatitis C patients in fee-for-service Medicare with Part D between 2014 and 2016. We used multinomial logistic regression to estimate adjusted odds ratios (aOR) of using DAAs by patient race/ethnicity and socioeconomic status. We estimated the model separately for 2014 and 2014-2016.

RESULTS: Of 281,810 Medicare patients who were followed to the end of 2016, a total of 90,419 (32.1\%) filled prescriptions for DAAs. In the 2014 analysis, blacks were less likely to use DAAs than whites $(\mathrm{aOR}=0.95$; $95 \% \mathrm{Cl}=0.91-0.99)$. However, in the 2014-2016 analysis, blacks had higher odds of using DAAs than whites ( $\mathrm{aOR}=1.24 ; 95 \% \mathrm{Cl}=1.22-1.27)$. No significant Hispanic-white gap existed during the study period. Income was positively associated with DAA use in both periods. Between 2014 and 2016, patients who received a Part D low-income subsidy had lower odds of using DAAs than patients who did not $(\mathrm{aOR}=0.90 ; 95 \% \mathrm{Cl}=0.88-0.92)$, and patients in areas with the higher income tertiles were more likely to initiate DAAs than those in areas with the lowest income tertile.

CONCLUSIONS: DAA use among Medicare patients remained far below the level needed to eradicate HCV. The black-white gap in HCV treatment was closed by 2016, but disparities by patient socioeconomic status remained. DAA use also varied by patient age and health risk, as well as across geographic regions. Continued efforts to improve DAA uptake in all HCV patients are needed to eradicate HCV.

J Manag Care Spec Pharm. 2019;25(11):1236-42

Copyright @ 2019, Academy of Managed Care Pharmacy. All rights reserved.

\section{What is already known about this subject}

- New hepatitis C virus (HCV) drugs-second-generation directacting antivirals (DAAs) — are highly effective but costly, raising a concern about limited access to DAAs by vulnerable populations. Previous studies of disparities in DAA uptake across patient groups showed mixed results; however, they were limited to using data from commercial health insurers or from the first year of DAAs.

\section{What this study adds}

The DAA treatment rate in a national cohort of Medicare patients with chronic hepatitis C increased between 2014 and 2016, but it remained far below the level needed to eradicate HCV.

A black-white gap in DAA use existed in 2014, but it was closed by 2016 , and no disparities between Hispanics and whites existed between 2014 and 2016.

Patients who had a Part D low-income subsidy or resided in ZIP codes with lower incomes were less likely to use DAAs than their counterparts.

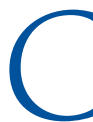
hronic hepatitis C is an important public health concern. It is a leading cause of costly and serious health conditions, such as cirrhosis and liver cancer. ${ }^{1}$ Hospitalizations and costs related to chronic hepatitis $C$ and liver diseases have been increasing during the past decade. ${ }^{2}$ Hepatitis C virus (HCV) caused more deaths in the United States than any other infectious disease in 2014. ${ }^{3}$ More than 3 million Americans are infected with HCV, and its prevalence is highest among baby boomers who were born between 1945 and $1965 .{ }^{1,4}$

The availability of new HCV drugs-second-generation direct-acting antivirals (DAAs) - has provided an unprecedented opportunity to stop the HCV epidemic. DAAs achieve cure rates over $90 \%$ in clinical trials and real-world practice, ${ }^{5-8}$ and they are equally efficacious for blacks and non-blacks in clinical trials. ${ }^{9}$ This is a significant improvement over the traditional interferon-based HCV therapy, which had about a $50 \%$ cure rate and poorer tolerance by blacks than whites. ${ }^{9-13}$ These DAA features have raised hope that HCV infection can be eradicated, ${ }^{14}$ and as a national goal, calls have been made for all HCV patients to take DAAs. ${ }^{15}$

However, DAAs were launched with high prices, and payers have restricted access to DAAs by requiring patients to have advanced fibrosis, to obtain DAA prescriptions from specialists (e.g., hepatologists or infectious disease doctors), and to pay high cost-sharing payments. ${ }^{16-18}$ These restrictions may disproportionally affect vulnerable populations, including racial/ethnic minorities and socioeconomically disadvantaged patients. 
Although DAA prices have fallen in recent years, they are still costly and access remains restricted. ${ }^{19}$

A few studies have examined racial/ethnic disparities in DAA uptake, but their findings have been mixed. ${ }^{20-23}$ A study of patients in 4 private health systems found no difference in DAA uptake between blacks and whites, ${ }^{20}$ while a study using data from an integrated delivery system found lower DAA uptake in blacks than in whites. ${ }^{21}$ In 2 studies of a national cohort, blacks had lower DAA uptake than whites in 2014, the first year of DAA availability. 22,23 The overall DAA uptake also has differed across studies, ${ }^{20-24}$ from $5.7 \%$ in a small cohort to $16.9 \%$ among patients from 4 health systems and $42.0 \%$ among patients from a large integrated system. ${ }^{20,21,24}$ These mixed results may be a result of using data from a specific health system or from the first year of DAAs, when the sofosbuvir plus interferon regime was dominant. Thus, the generalizability of the findings from previous studies is limited.

One study reported lower DAA uptake by patients with lower socioeconomic status, measured by the area-level poverty index. ${ }^{21}$ This work was limited to patients from 1 commercial insurer. How DAA uptake differs by patient characteristics in a national cohort in the years when more DAAs were available is unknown.

We examined DAA use between 2014 and 2016 in a national cohort of Medicare patients. Medicare has been the largest payer of DAAs because it enrolls many baby boomers-the group with the highest prevalence of $\mathrm{HCV}^{1,4,25}$ In addition, Medicare covers nonelderly people who are disabled and/or dually eligible for Medicare and Medicaid. ${ }^{18} \mathrm{HCV}$ infection is particularly prevalent among these beneficiaries. Thus, examining DAA uptake in Medicare is important.

We focused on the race/ethnicity and the socioeconomic status of Medicare beneficiaries. To examine whether disparities in DAA uptake changed over time, we analyzed 2 different time periods: 2014 and 2014-2016. In 2014, the dominant DAA regime was sofosbuvir plus interferon, which blacks tolerate poorly. ${ }^{9-12}$ Newer DAAs, which do not require concomitant interferon therapy, became available after October 2014. Thus, analyzing the 2014-2016 period informs us of racial/ethnic differences in DAA use during the years when more DAAs (other than sofosbuvir) were available.

Socioeconomically disadvantaged populations generally have greater barriers to access new medical technologies or effective treatments than their counterparts. ${ }^{26}$ This is a particularly important concern for HCV treatments because DAAs can affect the health of populations only when their use expands to all patient groups. ${ }^{27,28}$ Thus, discovering and monitoring disparities in DAA uptake by patient race/ethnicity and socioeconomic status is a key first step to promote equitable access to HCV treatments in Medicare.

\section{Methods}

\section{Study Population and Data Source}

The study population was HCV patients in fee-for-service (FFS) Medicare with Part D between 2014 and 2016. We requested the Centers for Medicare \& Medicaid Services (CMS) to identify patients with chronic hepatitis C from 100\% Medicare FFS claims (2014-2016) based on International Classification of Diseases, Ninth/Tenth Revision, Clinical Modification codes (ICD9-CM codes 070.44, 070.54, 070.70, and 070.71; ICD-10-CM codes B18.2, B19.20, and B19.21). A confirmed diagnosis required at least 1 inpatient or skilled nursing facility claim or at least 2 claims for outpatient visits in a given year (the 2-visit requirement excluded a rule-out diagnosis). This is the standard algorithm used by CMS to create condition indicators in Medicare Chronic Condition Warehouse data. ${ }^{29}$

We constructed 2 study samples from 2014 and 2014-2016, the most recent 3 years in which Medicare data are available since DAAs were introduced. The 2014 sample included patients diagnosed with HCV before or in 2014. This sample was used to assess DAA use in 2014, the first year of DAA availability. The 2014-2016 sample added patients newly diagnosed in 2015 or 2016 to the 2014 sample. This sample, which includes the years when DAAs other than sofosbuvir were available, was used to assess DAA uptake by the end of 2016 .

We identified DAA users from the 2014-2016 Medicare Prescription Drug Event File, which contains records of each outpatient prescription drug fill. Master Beneficiary Summary Files provided each beneficiary's demographics, residence (ZIP code), Part D low-income subsidy (LIS) status, and health risk factors. We acquired ZIP-level income and percentage with college education from the American Community Survey, which has been conducted annually since 2010 as a replacement of decennial Census long-form track data. County-level health care information was extracted from the Area Health Resource File.

\section{Key Outcome and Variables}

The key study outcome was the receipt of DAAs, defined as filling at least 1 prescription for elbasvir/grazoprevir, ledipasvir/sofosbuvir, ombitasvir/paritaprevir/ritonavir and dasabuvir, sofosbuvir (with peginterferon or simeprevir or daclastasvir), or sofosbuvir/velpatasvir during each analysis period (i.e., by the end of 2014 or the end of 2016). Each analysis included patients who could not be observed to the end of the period due to death or switching to Medicare Advantage. If those patients used a DAA before death or switching, they were categorized as DAA users. We created an indicator of loss to follow-up to distinguish those who died or switched to Medicare Advantage from nonusers. Thus, the study outcome was a 3-group categorical variable (DAA use, DAA nonuse, and loss to follow-up).

The explanatory variables of interest were patient race/ ethnicity and socioeconomic status. We categorized race/ 


\section{Racial/Ethnic and Socioeconomic Disparities in Use of Direct-Acting Antivirals Among Medicare Beneficiaries with Chronic Hepatitis C, 2014-2016}

TABLE 1 Baseline Characteristics of Medicare Beneficiaries with Chronic Hepatitis $C^{a}$

\begin{tabular}{|c|c|c|c|c|c|}
\hline \multirow[b]{2}{*}{ Characteristics } & \multicolumn{3}{|c|}{ Study Completed $(\mathrm{N}=281,830)$} & \multirow{2}{*}{$\begin{array}{l}\text { Lost to Follow-Up }{ }^{b} \\
\qquad(n=50,113)\end{array}$} & \multirow[b]{2}{*}{$P$ Value $^{c}$} \\
\hline & Users (n & $=90,419)$ & Nonusers $(n=191,411)$ & & \\
\hline \multicolumn{5}{|l|}{ Race/ethnicity } & $<0.001$ \\
\hline White & 60,078 & $(66.4)$ & $130,244 \quad(68.0)$ & $30,635 \quad(61.1)$ & \\
\hline Black & 22,875 & $(25.3)$ & $43,995 \quad(23.0)$ & $14,815 \quad(29.6)$ & \\
\hline Hispanic & 3,043 & $(3.4)$ & $6,682 \quad(3.5)$ & $2,064 \quad(4.1)$ & \\
\hline $\begin{array}{l}\text { Other (Asian/Pacific Islander, } \\
\text { North American Native, and } \\
\text { unknown) }\end{array}$ & 4,423 & $(4.9)$ & $10,490 \quad(5.5)$ & $2,599 \quad(5.2)$ & \\
\hline Low-income subsidy & 66,335 & $(73.4)$ & $148,807 \quad(77.7)$ & $40,981 \quad(81.8)$ & $<0.001$ \\
\hline \multicolumn{5}{|l|}{ Income (ZIP median income) } & $<0.001$ \\
\hline Lowest tertile & 30,116 & $(33.3)$ & $70,152 \quad(36.6)$ & $21,227 \quad(42.4)$ & \\
\hline Middle tertile & 31,812 & $(35.2)$ & $60,233 \quad(31.5)$ & $13,852 \quad(27.6)$ & \\
\hline Highest tertile & 28,491 & $(31.5)$ & $61,026 \quad(31.9)$ & $15,034 \quad(30.0)$ & \\
\hline \multicolumn{5}{|c|}{ Education (ZIP \% college educated) } & $<0.001$ \\
\hline Below mean ${ }^{\mathrm{d}}$ & 45,826 & $(50.7)$ & $104,381 \quad(54.5)$ & $28,855 \quad(57.6)$ & \\
\hline Above mean & 44,593 & $(49.3)$ & $87,030 \quad(45.5)$ & $21,258 \quad(42.4)$ & \\
\hline Female & 37,195 & $(41.1)$ & $78,139 \quad(40.8)$ & $19,035 \quad(38.0)$ & $<0.001$ \\
\hline \multicolumn{6}{|l|}{ Age } \\
\hline Mean (SD) & 60.3 & $(9.6)$ & $59.9 \quad(11.9)$ & $61.8 \quad(11.1)$ & $<0.001$ \\
\hline Median (IQR) & 61.0 & $(11.0)$ & $61.0 \quad(14.0)$ & $62.0 \quad(13.0)$ & \\
\hline \multicolumn{5}{|l|}{ Age group (years) } & $<0.001$ \\
\hline$<50$ & 10,183 & $(11.3)$ & $30,989 \quad(16.2)$ & $5,315 \quad(10.6)$ & \\
\hline 50 to $<55$ & 11,448 & $(12.7)$ & $23,504 \quad(12.3)$ & $5,848 \quad(11.7)$ & \\
\hline 55 to $<60$ & 18,031 & $(19.9)$ & $33,496 \quad(17.5)$ & $9,199 \quad(18.4)$ & \\
\hline 60 to $<65$ & 16,329 & $(18.1)$ & $29,193 \quad(15.3)$ & $9,026 \quad(18.0)$ & \\
\hline 65 to $<70$ & 22,594 & $(25.0)$ & $41,464 \quad(21.7)$ & $10,759 \quad(21.5)$ & \\
\hline$\geq 70$ & 11,834 & $(13.1)$ & $32,765 \quad(17.1)$ & $9,966 \quad(19.9)$ & \\
\hline \multicolumn{6}{|l|}{ Comorbidities } \\
\hline Charlson score, mean (SD) & 3.5 & $(3.1)$ & $4.1 \quad(3.6)$ & $6.0 \quad(1.2)$ & $<0.001$ \\
\hline \multicolumn{5}{|l|}{ Cirrhosis status } & $<0.001$ \\
\hline No cirrhosis & 66,830 & $(73.9)$ & $160,122 \quad(83.7)$ & $34,115 \quad(68.1)$ & \\
\hline Compensated cirrhosis & 14,805 & $(16.4)$ & $17,677 \quad(9.2)$ & $5,627 \quad(11.2)$ & \\
\hline Decompensated cirrhosis & 8,784 & $(9.7)$ & $13,612 \quad(7.1)$ & $10,371 \quad(20.7)$ & \\
\hline HIV & 6,886 & $(7.6)$ & $11,052 \quad(5.8)$ & $3,349 \quad(6.7)$ & $<0.001$ \\
\hline Cancer & 9,894 & $(10.9)$ & $26,304 \quad(13.7)$ & $8,806 \quad(17.6)$ & $<0.001$ \\
\hline Cardiovascular disease & 62,973 & $(69.6)$ & $148,594 \quad(77.6)$ & $42,173 \quad(84.2)$ & $<0.001$ \\
\hline Diabetes mellitus & 28,616 & $(31.6)$ & $69,331 \quad(36.2)$ & $21,787 \quad(43.5)$ & $<0.001$ \\
\hline Cataract or glaucoma & 15,775 & $(17.4)$ & $28,502 \quad(14.9)$ & $5,815 \quad(11.6)$ & $<0.001$ \\
\hline Renal disease & 19,641 & $(21.7)$ & $66,047 \quad(34.5)$ & $25,834 \quad(51.6)$ & $<0.001$ \\
\hline Mental disorder & 44,228 & $(48.9)$ & $114,780 \quad(60.0)$ & $31,339 \quad(62.5)$ & $<0.001$ \\
\hline $\begin{array}{l}\text { Osteoarthritis or rheumatoid } \\
\text { arthritis }\end{array}$ & 33,563 & $(37.1)$ & $76,578 \quad(40.0)$ & $20,102 \quad(40.1)$ & $<0.001$ \\
\hline Drug/substance use disorder & 39,355 & $(43.5)$ & $109,863 \quad(57.4)$ & $31,823 \quad(63.5)$ & $<0.001$ \\
\hline $\begin{array}{l}\text { Number of specialists in a } \\
\text { county (per } 1,000 \text { persons) }\end{array}$ & 1.2 & $(1.0)$ & $1.1 \quad(0.9)$ & $1.2 \quad(0.9)$ & $<0.001$ \\
\hline Region & & & & & $<0.001$ \\
\hline Northeast & 20,902 & $(23.1)$ & $39,663 \quad(20.7)$ & $8,999 \quad(18.0)$ & \\
\hline Midwest & 16,705 & (18.5) & $34,331 \quad(17.9)$ & $10,247 \quad(20.4)$ & \\
\hline South & 32,957 & $(36.4)$ & $73,844 \quad(38.6)$ & $20,098 \quad(40.1)$ & \\
\hline West & 19,855 & $(22.0)$ & $43,573 \quad(22.8)$ & $10,769 \quad(21.5)$ & \\
\hline
\end{tabular}

Note: All values are presented as $n$ (\%) unless indicated otherwise.

aBaseline characteristics in the year of diagnosis.

${ }^{b}$ This includes patients who were lost due to death $(n=26,695)$ and those lost due to switching to Medicare Advantage $(n=23,438)$.

${ }^{c} P$ values are based on chi-square tests for categorical variables and ANOVA tests for continuous variables.

${ }^{d}$ The mean percentage of college educated was $28.9 \%$ ( $\left.S D=10.6 \%\right)$

ANOVA = analysis of variance; $H I V=$ human immunodeficiency virus infection; $I Q R=$ interquartile range; $S D=$ standard deviation. 
ethnicity into 4 groups: blacks, Hispanics, whites, and others. We measured patient socioeconomic status by using Part D LIS status and ZIP-level income and education (percentage of college educated). Part D LIS is available to those with incomes $\leq 135 \%$ of the federal poverty level. It is an indicator of lowincome status, which is likely to be negatively associated with DAA use. However, because of the subsidies available to them, LIS beneficiaries have only nominal cost sharing for DAAs, ${ }^{18,23}$ which may increase DAA use. We also grouped beneficiaries into income tertiles based on the median household income of their ZIP codes. We used 2 categories for the education variable: above and below the mean percentage of college educated.

\section{Analysis}

We began by describing the cumulative DAA treatment rates by year. We then used chi square or ANOVA tests to compare patient demographics, health risk factors, and area-level variables between patients who initiated DAAs, those who did not, and those who were lost to follow-up.

We estimated adjusted odds ratios ( $\mathrm{aOR}$ ) by patient race/ ethnicity and socioeconomic status using multinomial logistic regression, which is appropriate for a categorical outcome variable. We used DAA nonuse as the baseline outcome category and obtained aOR of DAA use versus DAA nonuse, while accounting for loss to follow-up as a possible outcome.

All multinomial logistic models included patient race/ethnicity, ZIP-level socioeconomic status, LIS status, and control variables selected a priori for patient age, gender, and health risk factors. Previous studies showed that age and gender disparities existed in DAA uptake. High comorbidities (poorer health) tended to lower DAA use, while the presence of cirrhosis increased DAA uptake. ${ }^{20-23}$ We measured patient health risk by the Charlson Comorbidity Index score, presence of cirrhosis, and indicators of common chronic conditions among HCV patients (human immunodeficiency virus [HIV] infection, cancer, cardiovascular disease, diabetes mellitus, cataract or glaucoma, renal disease, mental disorder, osteoarthritis or rheumatoid arthritis, and drug/substance use disorder).

The models also controlled for the number of specialty doctors per 1,000 persons, which may be related to DAA use, given payers' requirements for prescriptions by specialists, and census region dummies to account for possible regional variation in DAA treatments. We included indicators of diagnosis year in the 2014-2016 analysis to account for different followup periods. We used SAS version 9.4 (SAS Institute, Cary, NC) to construct analytic files and STATA version 15.1 (StataCorp, College Station, TX) to perform regressions.

\section{Results}

Of 331,943 patients in the cohort, 26,695 (8.0\%) died, and 23,438 (7.0\%) switched to Medicare Advantage. Of the 281,810 patients who were followed to the end of the study period, 90,419 (32.1\%) filled DAA prescriptions. About $15.6 \%$ of the patients who were followed to the end of 2014 were treated with a DAA, and 32.1\% were treated by 2016 .

A small black-white gap in unadjusted DAA use existed in $2014(12.4 \%$ vs. $15.2 \% ; P<0.001)$. This gap was closed by 2016, when blacks had a higher unadjusted treatment rate than whites (34.2\% vs. $31.2 \% ; P<0.001)$.

Table 1 shows descriptive data for the study variables at baseline diagnosis year of each patient. Patients who initiated DAA therapy were more likely than those who did not to be black $(25.3 \%$ vs. $23.0 \%$; $P<0.001)$ or live in areas with more college-educated people (49.3\% vs. $45.5 \% ; P<0.001)$. DAA users were less likely to receive LIS $(73.4 \%$ vs. $77.7 \% ; P<0.001)$ or reside in areas with the lowest income tertile (33.3\% vs. 36.6\%; $P<0.001$ ) than nonusers.

Table 2 reports the results from multinomial logistic regressions. We focus on the first columns of each analysis period, which present aOR of DAA use versus nonuse. In 2014, blacks were less likely to use DAAs than whites $(\mathrm{aOR}=0.95 ; 95 \%$ confidence interval $[C I]=0.91-0.99 ; P=0.006$ ), but by 2016 , blacks had higher odds of using DAAs than whites ( $\mathrm{aOR}=1.24$; 95\% CI $=1.22-1.27 ; P<0.001)$. No Hispanic-white gap existed during the study period. Income was positively associated with DAA use in all periods. By 2016, LIS patients had lower odds of using DAAs than non-LIS patients ( $\mathrm{aOR}=0.90 ; 95 \%$ $\mathrm{CI}=0.88-0.92 ; P<0.001)$. The relationship between income and DAA uptake was nonlinear. Patients in areas with the higher income tertiles were more likely to initiate DAAs than those in areas with the lowest income tertile, but patients in the middle income tertile had higher odds of DAA use than those in the highest income tertile. DAA treatments by patient health risk showed similar patterns in both periods. Between 2014 and 2016, higher Charlson scores led to lower DAA uptake $(\mathrm{aOR}=0.95 ; 95 \% \mathrm{CI}=0.94-0.96 ; \mathrm{P}<0.001)$. Patients with compensated or decompensated cirrhosis were more likely to use DAAs than those without cirrhosis $(\mathrm{aOR}=3.09$; 95\% $\mathrm{CI}=2.98-3.20$ and $\mathrm{aOR}=3.41 ; 95 \% \mathrm{CI}=3.25-3.59$, respec tively; $P<0.001$ ).

\section{Discussion}

New DAAs offer an opportunity to stop the HCV epidemic. This goal can be realized only when DAA uptake increases in all patient groups. ${ }^{27,28}$ The treatment rate substantially increased when more DAAs became available in 2015 and 2016, but it was far below the level needed to achieve the eradication of HCV.15

We found that DAA treatment rates differed by patient race/ ethnicity. The finding of lower DAA use among blacks than whites in 2014 is consistent with previous work using data from the early years of DAA therapy. By 2016, however, blacks had the highest DAA treatment rate among all race/ethnicity 


\section{Racial/Ethnic and Socioeconomic Disparities in Use of Direct-Acting Antivirals Among Medicare Beneficiaries with Chronic Hepatitis C, 2014-2016}

\section{TABLE 2 Results from Multinomial Logistic Regressions}

\begin{tabular}{|c|c|c|c|c|c|c|}
\hline \multirow[b]{3}{*}{ Characteristics } & \multicolumn{6}{|c|}{ aOR $(95 \% \mathrm{CI})^{\mathrm{a}}$} \\
\hline & \multicolumn{3}{|c|}{$2014(n=192,610)$} & \multicolumn{3}{|c|}{$2014-2016(n=331,943)$} \\
\hline & \multicolumn{2}{|c|}{ DAA Use } & Lost to Follow-Up & DAA Use & \multicolumn{2}{|c|}{ Lost to Follow-Up } \\
\hline \multicolumn{7}{|l|}{ Race/ethnicity } \\
\hline White & \multicolumn{3}{|c|}{ Reference } & \multicolumn{3}{|c|}{ Reference } \\
\hline Black & 0.95 & $(0.91-0.99)^{b}$ & $0.84 \quad(0.80-0.88)^{b}$ & $1.24 \quad(1.22-1.27)^{\mathrm{b}}$ & 1.20 & $(1.17-1.23)^{\mathrm{b}}$ \\
\hline Hispanic & 1.04 & $(0.97-1.12)$ & $0.79 \quad(0.72-0.88)^{\mathrm{b}}$ & $1.00 \quad(0.95-1.04)$ & $1.14 \quad($ & $(1.08-1.21)^{b}$ \\
\hline Other & 0.95 & $(0.89-1.01)^{c}$ & $0.90 \quad(0.83-0.98)^{\mathrm{d}}$ & $0.87 \quad(0.83-0.90)^{b}$ & 1.00 & $(0.96-1.05)$ \\
\hline Low-income subsidy & 0.81 & $(0.78-0.83)^{b}$ & $1.08 \quad(1.03-1.14)^{\mathrm{b}}$ & $0.90 \quad(0.88-0.92)^{b}$ & $1.28 \quad$ & $(1.25-1.32)^{b}$ \\
\hline \multicolumn{7}{|l|}{ Income } \\
\hline Lowest tertile & \multicolumn{3}{|c|}{ Reference } & \multicolumn{3}{|c|}{ Reference } \\
\hline Middle tertile & 1.18 & $(1.13-1.24)^{\mathrm{b}}$ & $0.97 \quad(0.90-1.03)$ & $1.12 \quad(1.08-1.15)^{\mathrm{b}}$ & $0.81 \quad($ & $(0.78-0.84)^{b}$ \\
\hline Highest tertile & 1.08 & $(1.04-1.13)^{\mathrm{b}}$ & $0.98 \quad(0.93-1.02)$ & $1.06 \quad(1.03-1.08)^{b}$ & $0.87 \quad($ & $(0.85-0.90)^{b}$ \\
\hline \multicolumn{7}{|l|}{ Education } \\
\hline Below mean & \multicolumn{3}{|c|}{ Reference } & \multicolumn{3}{|c|}{ Reference } \\
\hline Above mean & 1.02 & $(0.98-1.06)$ & $1.01 \quad(0.95-1.06)$ & $1.03(1.00-1.05)^{\mathrm{d}}$ & 1.03( & $(1.00-1.06)^{\mathrm{d}}$ \\
\hline Female & 1.01 & $(0.98-1.04)$ & $0.87(0.84-0.91)^{\mathrm{b}}$ & $1.02(1.00-1.04)^{\mathrm{d}}$ & $0.95 \quad($ & $(0.93-0.97)^{b}$ \\
\hline \multicolumn{7}{|l|}{ Age group (years) } \\
\hline$<50$ & \multicolumn{3}{|c|}{ Reference } & \multicolumn{3}{|c|}{ Reference } \\
\hline $50-<55$ & 1.20 & $(1.14-1.27)^{\mathrm{b}}$ & $1.20(1.10-1.30)^{\mathrm{b}}$ & $1.39 \quad(1.35-1.44)^{\mathrm{b}}$ & 1.22 & $(1.17-1.27)^{\mathrm{b}}$ \\
\hline $55-<60$ & 1.29 & $(1.23-1.36)^{\mathrm{b}}$ & $1.34(1.25-1.45)^{\mathrm{b}}$ & $1.50 \quad(1.45-1.54)^{\mathrm{b}}$ & 1.33( & $(1.28-1.38)^{\mathrm{b}}$ \\
\hline $60-<65$ & 1.31 & $(1.24-1.38)^{b}$ & $1.52(1.41-1.64)^{\mathrm{b}}$ & $1.53 \quad(1.48-1.58)^{b}$ & $1.51 \quad($ & $(1.45-1.57)^{\mathrm{b}}$ \\
\hline $65-<70$ & 1.16 & $(1.10-1.23)^{\mathrm{b}}$ & $1.71 \quad(1.58-1.85)^{\mathrm{b}}$ & $1.41 \quad(1.36-1.45)^{\mathrm{b}}$ & $1.58 \quad$ & $(1.51-1.64)^{\mathrm{b}}$ \\
\hline$\geq 70$ & 0.74 & $(0.69-0.79)^{\mathrm{b}}$ & $2.69(2.48-2.91)^{\mathrm{b}}$ & $0.84 \quad(0.81-0.87)^{b}$ & $1.77 \quad($ & $(1.70-1.85)^{\mathrm{b}}$ \\
\hline \multicolumn{7}{|l|}{ Comorbidities } \\
\hline Charlson score & 0.95 & $(0.95-0.96)^{b}$ & $1.22(1.22-1.23)^{b}$ & $0.95 \quad(0.94-0.96)^{b}$ & $1.11 \quad($ & $(1.10-1.11)^{b}$ \\
\hline Cirrhosis status & & & & & & \\
\hline No cirrhosis & & & & & & \\
\hline Compensated & 3.09 & $(2.98-3.20)^{\mathrm{b}}$ & $1.13(1.07-1.19)^{\mathrm{b}}$ & $2.20 \quad(2.15-2.26)^{b}$ & $1.10 \quad($ & $(1.07-1.14)^{b}$ \\
\hline Decompensated & 3.41 & $(3.25-3.59)^{\mathrm{b}}$ & $2.54 \quad(2.42-2.66)^{b}$ & $2.25 \quad(2.17-2.32)^{b}$ & $2.00 \quad($ & $(1.93-2.07)^{\mathrm{b}}$ \\
\hline HIV & 1.42 & $(1.33-1.52)^{\mathrm{b}}$ & $0.37 \quad(0.34-0.40)$ & $1.63 \quad(1.56-1.69)^{\mathrm{b}}$ & $0.61 \quad($ & $(0.58-0.64)^{b}$ \\
\hline Cancer & 0.90 & $(0.86-0.94)^{b}$ & $0.94 \quad(0.90-0.99) \mathrm{d}$ & $0.91 \quad(0.88-0.93)^{b}$ & 0.99 & $(0.96-1.02)$ \\
\hline Cardiovascular disease & 0.78 & $(0.75-0.80)^{\mathrm{b}}$ & $0.93(0.88-0.99)^{\mathrm{d}}$ & $0.77 \quad(0.75-0.78)^{b}$ & $0.97 \quad($ & $(0.94-1.00)^{\mathrm{d}}$ \\
\hline Diabetes mellitus & 1.07 & $(1.03-1.10)^{\mathrm{b}}$ & $0.65(0.63-0.68)^{b}$ & $1.02(1.00-1.04)^{\mathrm{c}}$ & $0.79 \quad($ & $(0.78-0.81)^{\mathrm{b}}$ \\
\hline Cataract or glaucoma & 1.20 & $(1.16-1.24)^{b}$ & $0.44 \quad(0.41-0.47)^{b}$ & $1.16 \quad(1.14-1.19)^{\mathrm{b}}$ & $0.65 \quad($ & $(0.63-0.67)^{b}$ \\
\hline Renal disease & 0.67 & $(0.65-0.70)^{\mathrm{b}}$ & $2.83(2.71-2.96)^{b}$ & $0.64 \quad(0.63-0.65)^{b}$ & $1.31 \quad($ & $(1.28-1.35)^{\mathrm{b}}$ \\
\hline Mental disorder & 0.85 & $(0.82-0.87)^{\mathrm{b}}$ & $1.21 \quad(1.16-1.26)^{\mathrm{b}}$ & $0.77 \quad(0.75-0.78)^{b}$ & 1.08 & $(1.06-1.11)^{b}$ \\
\hline Osteoarthritis or RA & 1.00 & $(0.97-1.03)^{\mathrm{b}}$ & $0.70 \quad(0.68-0.73)^{b}$ & $1.01 \quad(0.99-1.03)$ & $0.88 \quad($ & $(0.86-0.90)^{b}$ \\
\hline Drug/substance use & 0.57 & $(0.55-0.59)^{\mathrm{b}}$ & $1.35 \quad(1.30-1.41)^{\mathrm{b}}$ & $0.59 \quad(0.58-0.60)^{b}$ & $1.16 \quad($ & $(1.13-1.19)^{\mathrm{b}}$ \\
\hline $\begin{array}{l}\text { Number of specialists in a } \\
\text { county (per } 1,000 \text { person) }\end{array}$ & 1.00 & $(0.99-1.02)$ & $0.96(0.93-0.98)^{b}$ & $1.02(1.01-1.03)^{\mathrm{b}}$ & 1.05 & $(1.04-1.06)^{b}$ \\
\hline Region & & & & & & \\
\hline Northeast & & & & & & \\
\hline Midwest & 0.95 & $(0.91-0.99)^{\mathrm{d}}$ & $1.04 \quad(0.98-1.10)$ & $0.99 \quad(0.97-1.02)$ & $1.32 \quad$ & $(1.27-1.36)^{\mathrm{b}}$ \\
\hline South & 0.86 & $(0.83-0.89)^{\mathrm{b}}$ & $1.06(1.01-1.12)^{\mathrm{d}}$ & $0.89 \quad(0.87-0.91)^{b}$ & $1.17 \quad($ & $(1.14-1.21)^{b}$ \\
\hline West & 0.80 & $(0.77-0.84)^{b}$ & $0.99 \quad(0.94-1.05)$ & $0.84 \quad(0.82-0.86)^{b}$ & 1.12 & $(1.08-1.16)^{b}$ \\
\hline Diagnosis year & & & & & & \\
\hline 2014 & & - & - & & & \\
\hline 2015 & & - & - & $0.66 \quad(0.64-0.67)^{b}$ & $0.61 \quad($ & $(0.60-0.63)^{b}$ \\
\hline 2016 & & - & - & $0.33 \quad(0.32-0.34)^{b}$ & $0.25 \quad($ & $(0.24-0.26)^{b}$ \\
\hline $\begin{array}{l}\text { aThe base outcome category is } \\
b P<0.01 \text {. } \\
c P<0.10 \text {. } \\
d P<0.05 \text {. } \\
\text { aOR=adjusted odds ratio; } C I=\end{array}$ & & us the reporte & are DAA nonuse vs & DAA nonuse vs. lo & $p$ & \\
\hline
\end{tabular}




\section{Racial/Ethnic and Socioeconomic Disparities in Use of Direct-Acting Antivirals Among Medicare Beneficiaries with Chronic Hepatitis C, 2014-2016}

groups. This is probably because a widely used DAA regime in 2014 required interferon, while newer DAAs available in the later years did not. Blacks do not seem to respond well and/or seem to have poor tolerance for interferon therapy., 2,-12,23 Thus, the increase in DAA use in blacks in the later years may reflect pent-up demand for HCV treatment among black patients. The finding of a disappearing gap between blacks and whites is encouraging. However, the DAA use rates were still low in all race/ethnicity groups, and the differences in the rates were relatively small. This suggests room for improvement in access to HCV treatments across all race/ethnicity groups.

Patient socioeconomic status was an important factor related to DAA use. LIS beneficiaries were less likely to use DAAs than non-LIS beneficiaries. This finding is somewhat surprising considering that LIS beneficiaries have only nominal cost sharing for DAAs in Part D. It implies that low-income patients face barriers to use of DAAs other than out-of-pocket spending. The results for income and education also indicated that socioeconomically disadvantaged patients had limited access to DAAs. This disparity may be a result of differences in health literacy or access to health care systems by patient socioeconomic status. While expected, this finding is concerning given that the HCV epidemic can be effectively addressed only when HCV treatments expand to all patient groups. It underscores that more efforts are needed to achieve equitable access to HCV treatments.

Patients with higher comorbidities tended to have lower DAA uptake rates. These patients may have competing demands for treating other conditions. The higher uptake rate among patients with HIV infection reflects that these patients are a high priority group for DAA treatments because HCV and HIV have common routes of transmission. ${ }^{30}$ Low uptake rates among patients without cirrhosis and those with drug/ substance disorders are consistent with the expectation that payers' restrictions on DAA use (requiring patients to have advanced fibrosis and drug/substance abstinence) deter DAA uptake. The positive association between the availability of specialty doctors and DAA use may be a result of requirements by plans for specialists' prescriptions. Future studies examining the effect of payers' coverage policies on DAA uptake would be informative in exploring ways to increase access to DAAs.

\section{Limitations}

This study has some limitations to consider. First, Medicare claims do not record clinical information, such as fibrosis stage and HCV genotype. Thus, we could not control for those factors. Second, we did not have information on specific requirements for DAA use by each Part D plan. We could not assess the effect of plan requirements on DAA uptake. Third, we measured socioeconomic status at the ZIP code level, which may not correctly represent socioeconomic status of all the residents. Any residual socioeconomic status (i.e., difference between individual and ZIP-level socioeconomic status) may have been captured in other explanatory variables, such as race. Finally, our findings are not generalizable to Medicare Advantage enrollees, patients in commercial insurance settings, or trends in DAA use after 2016.

\section{Conclusions}

The DAA use rate among Medicare patients increased during the first 3 years of DAA availability, but it remained low in 2016. The black-white gap in HCV treatment was closed by 2016, but disparities by patient socioeconomic status remained. Continued efforts to improve DAA uptake in all patients will help accomplish the national goal of $\mathrm{HCV}$ eradication.

\section{Authors}

JEAH JUNG, PhD, MPH, Department of Health Policy and Administration, The Pennsylvania State University, University Park. PING DU, MD, PhD, Department of Public Health Sciences, College of Medicine; LAN KONG, PhD, Department of Public Health Sciences, College of Medicine; and THOMAS RILEY, III, MD, MS, FAASLD, Department of Medicine, College of Medicine, The Pennsylvania State University, Hershey. ROGER FELDMAN, PhD, Division of Health Policy and Management, School of Public Health, University of Minnesota, Minneapolis.

AUTHOR CORRESPONDENCE: Jeah Jung, PhD, MPH, Department of Health Policy and Administration, The Pennsylvania State University, 601 E. Ford Bldg., University Park, PA 16802. Tel.: 814.863.8129; E-mail:kuj11@psu.edu.

\section{DISCLOSURES}

This study was supported by the National Institute on Aging (1 R01 AG055636$01 \mathrm{Al}$ ) and National Institute of Child Health \& Human Development (R24 HD04025). The funders had no role in the design and conduct of the study; collection, management, analysis, and interpretation of the data; preparation, review, or approval of the manuscript; and decision to submit the manuscript for publication. Feldman owns stock in Gilead Sciences and Abbvie. No other potential competing interest exists.

\section{REFERENCES}

1. Centers for Disease Control and Prevention. Surveillance for viral hepatitis-United States, 2014. June 22, 2016. Available at: https://www.cdc.gov/ hepatitis/statistics/2014surveillance/commentary.htm\#summary. Accessed September 25, 2019.

2. Xu F, Tong X, Leidner AJ. Hospitalizations and costs associated with hepatitis $C$ and advanced liver disease continue to increase. Health Aff (Millwood). 2014;33(10):1728-35.

3. Centers for Disease Control and Prevention. Hepatitis C kills more Americans than any other infectious disease. 2016. Available at: http:// www.cdc.gov/media/releases/2016/p0504-hepc-mortality.html. Accessed September 25, 2019

4. Moorman AC, Gordon SC, Rupp LB, et al. Baseline characteristics and mortality among people in care for chronic viral hepatitis: the chronic hepatitis cohort study. Clin Infect Dis. 2013;56(1):40-50. 


\section{Racial/Ethnic and Socioeconomic Disparities in Use of Direct-Acting Antivirals Among Medicare Beneficiaries with Chronic Hepatitis C, 2014-2016}

5. Afdhal N, Zeuzem S, Kwo P, et al. Ledipasvir and sofosbuvir for untreated HCV genotype 1 infection. N Engl J Med. 2014;370(20):1889-98.

6. Afdhal N, Reddy KR, Nelson DR, et al. Ledipasvir and sofosbuvir for previously treated HCV genotype 1 infection. N Engl J Med. 2014;370(16):1483-93.

7. Yin S, Barker L, White JZ, Jiles RB. Sofosbuvir-based regimens for chronic hepatitis $C$ in a well-insured U.S. population: patient characteristics, treatment adherence, effectiveness, and health care costs, 2013-2015. J Manag Care Spec Pharm. 2019;25(2):195-210. Available at: https://www.jmcp.org/ doi/10.18553/jmcp.2019.25.2.195.

8. Andres J, Lott S, Qureshi K. Eight-week outcomes of ledipasvir/sofosbuvir in noncirrhotic treatment-naive patients with hepatitis $C$ : analysis of pharmacy-based data. J Manag Care Spec Pharm. 2018;24(1):23-28. Available at: https://www.jmcp.org/doi/10.18553/jmcp.2018.24.1.23.

9. Schaeffer S, Khalili M. Reasons for HCV non-treatment in underserved African Americans: implications for treatment with new therapeutics. Ann Hepatol. 2015;14(2):234-42.

10. Melia MT, Muir AJ, McCone J, et al. Racial differences in hepatitis C treatment eligibility. Hepatology. 2011;54(1):70-78.

11. Borum ML, Igiehon E, Shafa S. African Americans may differ in their reasons for declining hepatitis $C$ therapy compared to non-African Americans. Dig Dis Sci. 2009;54(7):1604; author reply 1604-05.

12. Institute for Clinical and Economic Review. The comparative clinical effectiveness and value of simeprevir and sofosbuvir in the treatment of chronic hepatitis $C$ infection. Final report. April 15, 2014. Available at: https://icer-review.org/wp-content/uploads/2016/02/CTAF_Hep_C_Aprl4_ final.pdf. Accessed September 25, 2019.

13. Joseph AM. Treating hepatitis C: introduction and background. The Incidental Economist. June 12, 2014. Available at: http://theincidentaleconomist.com/wordpress/treating-hepatitis-c-introduction-and-background/. Accessed September 25, 2019.

14. Sussman NL, Remien CH, Kanwal F. The end of hepatitis C. Clin Gastroenterol Hepatol. 2014;12(4):533-36.

15. National Academies of Sciences, Engineering, and Medicine. A National Strategy for the Elimination of Hepatitis B and C. Phase Two Report. Washington, DC: The National Academies Press; 2017. Available at: http://www.nationalacademies.org/hmd/reports/2017/national-strategy-for-the-elimination-ofhepatitis-b-and-c.aspx. Accessed September 25, 2019.

16. Canary LA, Klevens RM, Holmberg SD. Limited access to new hepatitis $C$ virus treatment under state Medicaid programs. Ann Intern Med. 2015;163(3):226-28.

17. Barua S, Greenwald R, Grebely J, Dore GJ, Swan T, Taylor LE. Restrictions for Medicaid reimbursement of sofosbuvir for the treatment of hepatitis $C$ virus infection in the United States. Ann Intern Med. 2015;163(3):215-23.
18. Jung JK, Feldman R, Cheong C, Du P, Leslie D. Coverage for hepatitis C drugs in Medicare Part D. Am J Manag Care. 2016;22(6 Spec No.):SP220-26.

19. Weiner, J, Lina, BP. Cost-effective screening and treatment of hepatitis C. Leonard Davis Institute of Health Economics. September 17, 2018. Available at: https://ldi.upenn.edu/brief/cost-effective-screening-and-treatment-hepatitis-c. Accessed September 25, 2019.

20. Wong RJ, Jain MK, Therapondos G, et al. Race/ethnicity and insurance status disparities in access to direct acting antivirals for hepatitis $C$ virus treatment. Am J Gastroenterol. 2018;113(9):1329-38.

21. Marcus JL, Hurley LB, Chamberland S, et al. Disparities in initiation of direct-acting antiviral agents for hepatitis $C$ virus infection in an insured population. Public Health Rep. 2018;133(4):452-60.

22. Kanwal F, Kramer JR, El-Serag HB, et al. Race and gender differences in the use of direct acting antiviral agents for hepatitis $C$ virus. Clin Infect Dis. 2016;63(3):291-99.

23. Jung J, Feldman R. Racial-ethnic disparities in uptake of new hepatitis $C$ drugs in Medicare. J Racial Ethn Health Disparities. 2017;4(6):1147-158.

24. Spradling PR, Xing J, Rupp LB, et al. Uptake of and factors associated with direct-acting antiviral therapy among patients in the chronic hepatitis cohort study, 2014 to 2015. J Clin Gastroenterol. 2018;52(7):641-47.

25. IMS Institute for Health Informatics. Medicines use and spending in the U.S. A review of 2015 and outlook to 2020. April 2016. Available at: https:// morningconsult.com/wp-content/uploads/2016/04/IMS-Institute-US-DrugSpending-2015.pdf. Accessed September 25, 2019.

26. Weiss D, Rydland HT, Øversveen E, Jensen MR, Solhaug S, Krokstad S. Innovative technologies and social inequalities in health: a scoping review of the literature. PLoS One. 2018;13(4):e0195447.

27. Hickman M, De Angelis D, Vickerman P, Hutchinson S, Martin NK. Hepatitis $C$ virus treatment as prevention in people who inject drugs: testing the evidence. Curr Opin Infect Dis. 2015;28(6):576-82.

28. Aspinall EJ, Hutchinson SJ, Janjua NZ, et al. Trends in mortality after diagnosis of hepatitis $C$ virus infection: an international comparison and implications for monitoring the population impact of treatment. J Hepatol. 2015;62(2):269-77.

29. Chronic Conditions Data Warehouse. Other chronic or potentially disabling conditions: viral hepatitis (general). Available at: https://www.ccwdata.org/web/guest/condition-categories. Accessed September 25, 2019

30. Platt L, Easterbrook P, Gower E, et al. Prevalence and burden of HCV co-infection in people living with HIV: a global systematic review and metaanalysis. Lancet Infect Dis. 2016;16(7):797-808. 